\title{
Development of Foam One-Part Geopolymers with Enhanced Thermal Insulation Performance and Low Carbon Dioxide Emissions
}

\author{
Zahra Abdollahnejad $^{1, a *}$, Fernando Pacheco-Torgal ${ }^{1, b}$ \\ and José Barroso de Aguiar ${ }^{1, c}$ \\ ${ }^{1}$ C-TAC Research Centre, University of Minho, Portugal \\ atolumahvash@gmail.com, btorgal@civil.uminho.pt, caguiar@civil.uminho.pt
}

\begin{abstract}
Keywords: Foam agents; geopolymers; compressive strength; thermal conductivity; carbon dioxide emissions; cost efficiency
\end{abstract}

\begin{abstract}
Buildings are responsible for more than $40 \%$ of the energy consumption and greenhouse gas emissions. Thus, increasing building energy efficiency is one the most cost-effective ways to reduce emissions. The use of thermal insulation materials could constitute the most effective way of reducing heat losses in buildings by minimising heat energy needs. These materials have a thermal conductivity factor, $\mathrm{k}(\mathrm{W} / \mathrm{m} . \mathrm{K})$ lower than 0.065 while other insulation materials such as aerated concrete can go up to 0.11 . Current insulation materials are associated with negative impacts in terms of toxicity. Polystyrene, for example contains anti-oxidant additives and ignition retardants. In addition, its production involves the generation of benzene and chlorofluorocarbons. Polyurethane is obtained from isocyanates, which are widely known for their tragic association with the Bhopal disaster. Besides current insulation materials releases toxic fumes when subjected to fire. This paper presents experimental results on one-part geopolymers. It also includes global warming potential assessment and cost analysis. The results show that only the use of aluminium powder allows the production mixtures with a high compressive strength however its high cost means they are commercially useless when facing the competition of commercial cellular concrete. The results also show that one-part geopolymer mixtures based on $26 \% \mathrm{OPC}+58.3 \% \mathrm{FA}+8 \% \mathrm{CS}$ $+7.7 \% \mathrm{CH}$ and $3.5 \%$ hydrogen peroxide constitute a promising cost efficient $\left(67 \mathrm{euro} / \mathrm{m}^{3}\right)$, thermal insulation solution for floor heating systems with low global warming potential of $443 \mathrm{KgCO} 2 \mathrm{eq} / \mathrm{m}^{3}$.
\end{abstract}

\section{Introduction}

The increasing demand for worldwide energy, is a major cause for the unsustainable development of our Planet. Between 2007 and 2030 energy demand have grown about $40 \%$ reaching 16.8 billion tonnes of equivalent petroleum-TEP [1].

The rise in energy consumption has two main reasons, the increase in world population and the fact that there are an increasing number of people with access to electricity. Currently, 1.5 billion people still have no access to electricity [2].

Besides since urban human population will almost double, increasing from approximately 3.4 billion in 2009 to 6.4 billion in 2050 [3] this will dramatically increase electricity demand. Given that buildings consume throughout their life cycle, more than $40 \%$ of all energy produced [4], we can easily see the high energy saving potential that this subsector may represent in terms of reducing carbon dioxide emissions.

The European Energy Performance of Buildings Directive 2002/91/EC (EPBD) has been recast in the form of the 2010/31/ EU by the European Parliament on 19 May 2010. One of the new aspects of the EPBD that reflects an ambitious agenda on the reduction of the energy consumption is the introduction of the concept of nearly zero-energy building [5].

The use of thermal insulation materials constitutes the most effective way of reducing heat losses in buildings thus reducing heat energy needs thus contributing to the nearly zero energy target. These materials are very important for the building material industry representing a 21 billion $€$ market share [6]. However, most current insulation materials are associated with negative impacts in terms of toxicity. Polystyrene, for example contains anti-oxidant additives and ignition 
retardants, additionally, its production involves the generation of benzene and chlorofluorocarbons. On the other hand, polyurethane is obtained from isocyanates, which are widely known for their tragic association with the Bhopal disaster. Besides, they release toxic fumes when subjected to fire [7]. Besides recently the European Union recently approved the Regulation (EU) 305/2011 [8] related to the Construction Products Regulation (CPR) that will replace the current Directive 89/106/CEE, already amended by Directive 1993/68/EEC, known as the Construction Products Directive (CPD). Investigations in the field of geopolymers had an exponential increase after the research results of Davidovits [9] who developed and patented binders obtained from the alkaliactivation of metakaolin, having named it after the term "geopolymer" in 1978.

For the chemical designation of the geopolymer Davidovits suggested the name "polysialates", in which Sialate is an abbreviation for aluminosilicate oxide. However Provis and Van Deventer [10] mentioned that the sialate nomenclature "implies certain aspects of the geopolymer gel structure which do not correspond to reality".

Despite all the investigations published on these materials in the last decades some aspects still needed to be further investigated especially concerning durability performance [11-13].

The discovery of one-part geopolymers is considered a key event on the evolution of low carbon geopolymer technology, however they were associated with very low compressive strength [14, 15]. Some authors recently investigated these materials having reported a 28 days curing compressive strength of $27 \mathrm{MPa}$ by using fly ash and just $30 \%$ OPC [16].

This paper discloses results of a study on the properties of one-part foam geopolymers. It also includes global warming potential assessment and cost analysis.

\section{Experimental work}

\section{Materials and mix design}

The mix composition of one-part geopolymer mortars include kaolin, fly ash, ordinary Portland cement (OPC), sodium hydroxide, calcium hydroxide $\left(\mathrm{Ca}(\mathrm{OH})_{2}\right)$, water and superplasticizer (Table 1). A mixture of kaolin and sodium hydroxide calcined in a furnace at $650{ }^{\circ} \mathrm{C}$ during 140 minutes is referred as calcined stuff (CS) $[16,17]$. Three foaming agents were used namely aluminium powder $(0.5 \%-1.5 \%), \mathrm{NaBO}_{3}(3 \%-5 \%)$ and $\mathrm{H}_{2} \mathrm{O}_{2}(3 \%-5 \%)$. The OPC is of class I $42.5 \mathrm{R}$ type with clinker content between $95 \%$ and $100 \%$, and specific weight of $3.15 \mathrm{~g} / \mathrm{cm}^{3}$. The super-plasticizer (SP) used in the investigation was BASF 617 used to maintain a uniform consistency between different mixtures. The fly ash was supplied from Sines-EDP, and based on NP EN 450-1, it belongs to class $\mathrm{B}$ and has fineness modulus of class N. Its specific weight was $2.42 \mathrm{~g} / \mathrm{cm}^{3}$.

Table 1. Composition of one-part geopolymer mixtures

\begin{tabular}{|c|c|c|c|c|c|c|}
\hline $\begin{array}{c}\text { OPC } \\
(\%)\end{array}$ & $\begin{array}{l}\text { Fly } \\
\text { ash } \\
(\%)\end{array}$ & $\begin{array}{l}\text { Calcined kaolin } \\
\text { and sodium } \\
\text { hydroxide }(\%)\end{array}$ & $\begin{array}{c}\mathrm{Ca}(\mathrm{OH})_{2} \\
(\%)\end{array}$ & $\begin{array}{c}\text { Sand } \\
(\%)\end{array}$ & $\begin{array}{c}\text { SP } \\
(\%)\end{array}$ & $\mathrm{w} / \mathrm{b}$ \\
\hline 100 & - & - & - & \multirow{5}{*}{80} & \multirow{5}{*}{0.8} & \multirow{5}{*}{0.35} \\
\hline 30 & 70 & - & - & & & \\
\hline 30 & 58.3 & 4 & 7.7 & & & \\
\hline 26 & 58.3 & 8 & 7.7 & & & \\
\hline 18 & 58.3 & 16 & 7.7 & & & \\
\hline
\end{tabular}

\section{Experimental procedures}

Compressive strength was approached based on NP EN 195-1. The compressive strength was obtained from a average of three cubic specimens with dimensions of $50 \times 50 \times 50 \mathrm{~mm}^{3}$ cured during 28 days were tested.

Bulk density was assessed according to ASTM C373-78. 
Thermal conductivity was assessed utilizing an Alambeta instrument developed at the Technical University of Liberec, Czech Republic. This computer controlled instrument, called ALAMBETA, works in the semi-automatic regime, calculates all measurement statistic parameters and exhibits the instrument auto diagnostics. During the measurements, the initial temperature of the samples and the relative humidity were in the range of 22 to $24^{0} \mathrm{C}$ and 55 to $65 \%$, respectively.

\section{Results and discussion}

\section{Compressive strength}

Results of compressive strength of one-part geopolymer mortars are shown in Fig 1. For mortars based only in Portland cement, increase of the aluminium content leads to a decrease in compressive strength. Except when the aluminium content increases from $1.2 \%$ to $1.5 \%$ which leads to increase of compressive strength. When the $\mathrm{NaBO}_{3}$ is used as foaming agent in Portland cement mortars a trend on compressive strength decreased with foaming agent increased. Although one exception is detected when $\mathrm{NaBo}_{3}$ increased from $3 \%$ to $3.5 \%$ that leads to an increase in compressive strength. Comparing the performance of the different foaming agents on Portland cement mortars it is observed that the higher compressive strength $(20.24 \mathrm{MPa})$ was recorded for a $0.5 \%$ AL content.

Concerning the mixture 30 OPC $70 \mathrm{FA}$, the increase of the aluminium content results in a decrease in compressive strength. Except when it increased from $1 \%$ to $1.2 \%$ lead to slight compressive strength increase. When the $\mathrm{NaBO}_{3}$ is used a trend on compressive strength decrease with foaming agent increase can be found. Respect to the use of $\mathrm{H}_{2} \mathrm{O}_{2}$ the increase of foaming agent leads to an increase in compressive strength with one exception. The exceptions were found when the $\mathrm{NaBO}_{3}$ content increased from $1 \%$ to $2 \%$ and $4.5 \%$ to $5 \%$. Since, no specific trend was observed in compressive strength of the mixture 30 OPC_58.3 FA_4 CS_7.7 CH that used $\mathrm{H}_{2} \mathrm{O}_{2}$. Comparing the performance of the different foaming agents the higher compressive strength $(7 \mathrm{MPa})$ took place for a $0.5 \%$ AL content. Additionally, two similar compressive strength recorded for this mixture with $1 \%$ AL (6 MPa) and 1.2\% AL (6.04 MPa).

Results of compressive strength in mixture 26 OPC_58.3 FA_8 CS_7.7 CH show that there is an increase in compressive strength when the $\mathrm{Al}$ content increased. Although an exception discovered when the aluminium content increased from $0.5 \%$ to $1 \%$. Since, no specific trend was observed in compressive strength of the mixture 30 OPC_58.3 FA_4 CS_7.7 CH that used $\mathrm{NaBO}_{3}$. Concerning the mixture o18 OPC_58.3 FA_16 CS_7.7 $\mathrm{CH}$, an increase in the aluminium content leads to a decrease in compressive strength. When the $\mathrm{NaBO}_{3}$ is used as foaming agent a trend on compressive strength increase with foaming agent increase can be noticed. Respect to the use of $\mathrm{H}_{2} \mathrm{O}_{2}$ the increase of foaming agent results in reduction of compressive strength. By comparing the performance of the different foaming agents it can be concluded that the higher compressive strength $(6.11 \mathrm{MPa})$ was measured for a $5 \% \mathrm{NaBO}_{3}$ content.

The overall results show that several mixtures show a compressive strength similar to the one of commercial cellular concrete blocks $(6.5 \mathrm{MPa})$. However most mixtures comply with the compressive strength requirement $(\geq 1.4 \mathrm{MPa})$ of the grades 4 and 5 of the Korean Industrial Standard code for foam concrete for floor heating systems [17].

\section{Bulk density}

The results of bulk density of one-part geopolymer mortars are shown in Fig 2. For mortars based only in Portland cement an increment in the aluminium content leads to a decrease in bulk density. When the $\mathrm{NaBO}_{3}$ is employed in Portland cement mortars a trend on bulk density decrease with foaming agent content increase can be noticed. Concerning the use of $\mathrm{H}_{2} \mathrm{O}_{2}$ the increase of foaming agent show a minor increase in the bulk density but when the foaming agent is increased between $4 \%$ to $4.5 \%$ slight decrease in bulk density was detected. Regarding the performance of the different foaming agents on Portland cement mortars it is revealed that the lowest bulk density $\left(1067 \mathrm{~kg} / \mathrm{m}^{3}\right)$ recorded for a $3 \% \mathrm{H}_{2} \mathrm{O}_{2}$ content. 


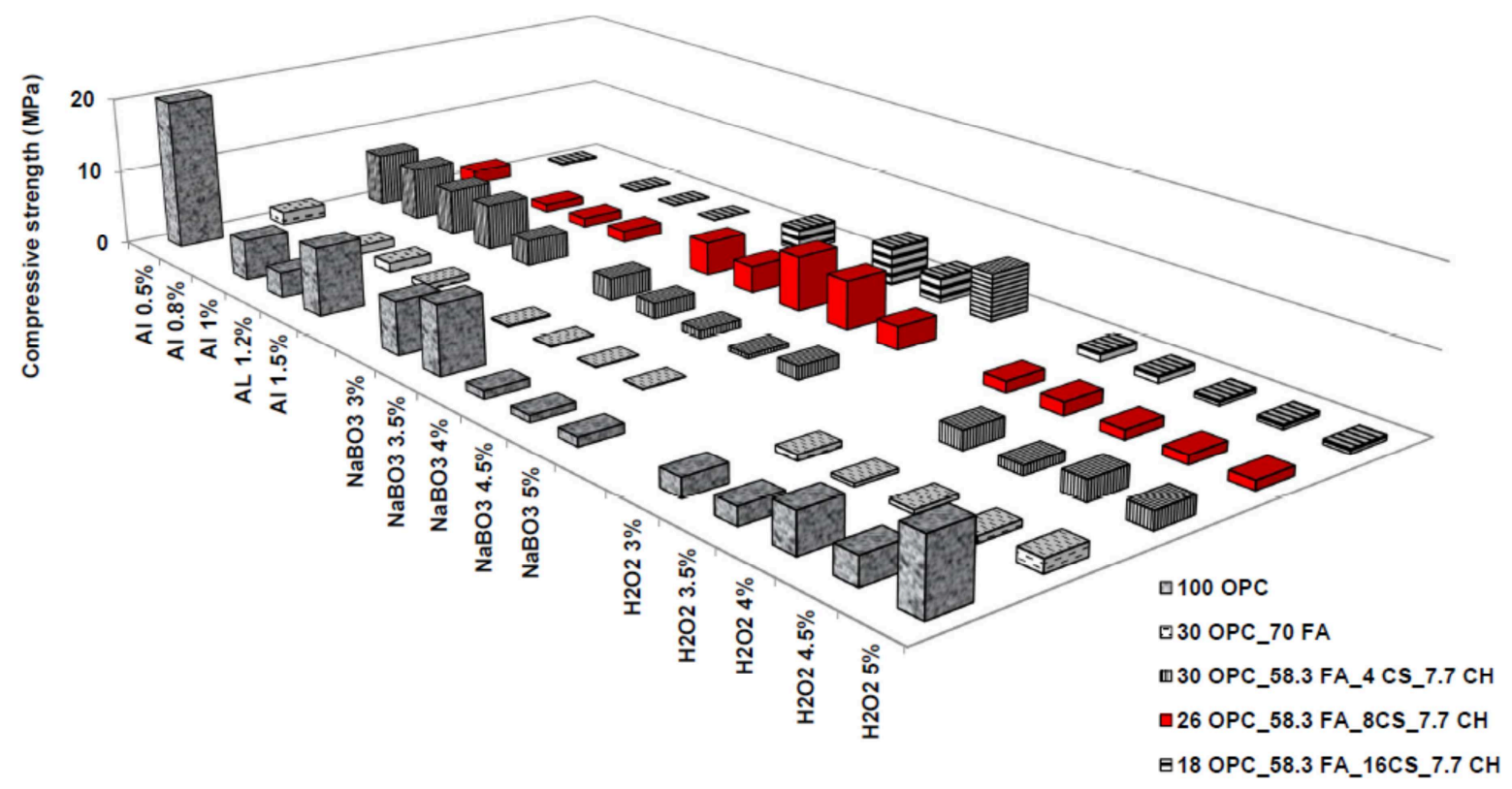

Fig 1. Compressive strength

Concerning the mixture 30 OPC_70 FA the increase of the aluminium content leads to decrease in bulk density. Except when it increases from $1 \%$ to $1.2 \%$ lead to the slight bulk density increase. When the $\mathrm{NaBO}_{3}$ is used a trend can be noticed on bulk density increase. Regarding the use of $\mathrm{H}_{2} \mathrm{O}_{2}$ the increase of foaming agent from $3 \%$ to $4 \%$ show a decrease in the bulk density but when the foaming agent is increased above $4 \%$ an increase in the bulk density were registered. The lowest bulk density $\left(785 \mathrm{~kg} / \mathrm{m}^{3}\right)$ took place for a $4.5 \% \mathrm{H}_{2} \mathrm{O}_{2}$ content.

In respect to results of bulk density for mixture 30 OPC_58.3 FA_4 CS_7.7 CH increasing the aluminium content leads to reduce bulk density. Concerning the use of $\mathrm{H}_{2} \mathrm{O}_{2}$ the increase of foaming agent show a constant trend in bulk density results. Comparing the obtained results by using different foaming agents it is observed that the lowest bulk density $\left(821 \mathrm{~kg} / \mathrm{m}^{3}\right)$ took place for a $1.2 \%$ AL content.

Concerning the mixture 26 OPC_58.3 FA_8 CS_7.7 CH an increasing the aluminium content from $0.5 \%$ to $1 \%$ leads to slight increase in bulk density. By increasing Al content more than $0.8 \%$ results in constant trend in bulk density and no increase was detected. Comparing the results obtained from using different foaming agents, it is revealed that the lowest bulk density $\left(980 \mathrm{~kg} / \mathrm{m}^{3}\right)$ measured for a $4 \% \mathrm{H}_{2} \mathrm{O}_{2}$ content.

Concerning the mixture 18 OPC_58.3 FA_16 CS_7.7 CH. the increase of the aluminium content leads to reduce of bulk density. Increasing of $\mathrm{NaBo}_{3}$ content, results in reduction of bulk density. However some exceptions were detected. Except from $4.5 \%$ to $5 \%$ which show an increase in the bulk density. The lowest bulk density $\left(654 \mathrm{~kg} / \mathrm{m}^{3}\right)$ recorded for a $4.5 \% \mathrm{H}_{2} \mathrm{O}_{2}$ content.

\section{Thermal conductivity}

Fig 3 presents the results of thermal conductivity performance of some one part foam geopolymer mixtures. Thermal conductivity test was not carried out on all one-part geopolymer mixtures. Instead, two criteria were considered to select the mixtures for thermal conductivity testing, a) Mixtures with compressive strength greater than $2 \mathrm{MPa}$; b) Mixtures with bulk density lower than $1100 \mathrm{~kg} / \mathrm{m}^{3}$.

The lowest thermal conductivity performance $(0.132 \mathrm{~W} / \mathrm{m} . \mathrm{K})$ was recorded for one-part geopolymer mortars, in mix $30 \mathrm{OPC}+58.3 \mathrm{FA}+4 \mathrm{CS} \_7.7 \mathrm{CH}$ and $1.2 \% \mathrm{Al}$. As the thermal conductivity of commercial autoclaved aerated concrete masonry blocks (Ytong) is around $(0.17$ $\mathrm{W} / \mathrm{m} . \mathrm{K}$ ), similar thermal conductivity performances can be considered acceptable for thermal insulator like cementitious materials. 


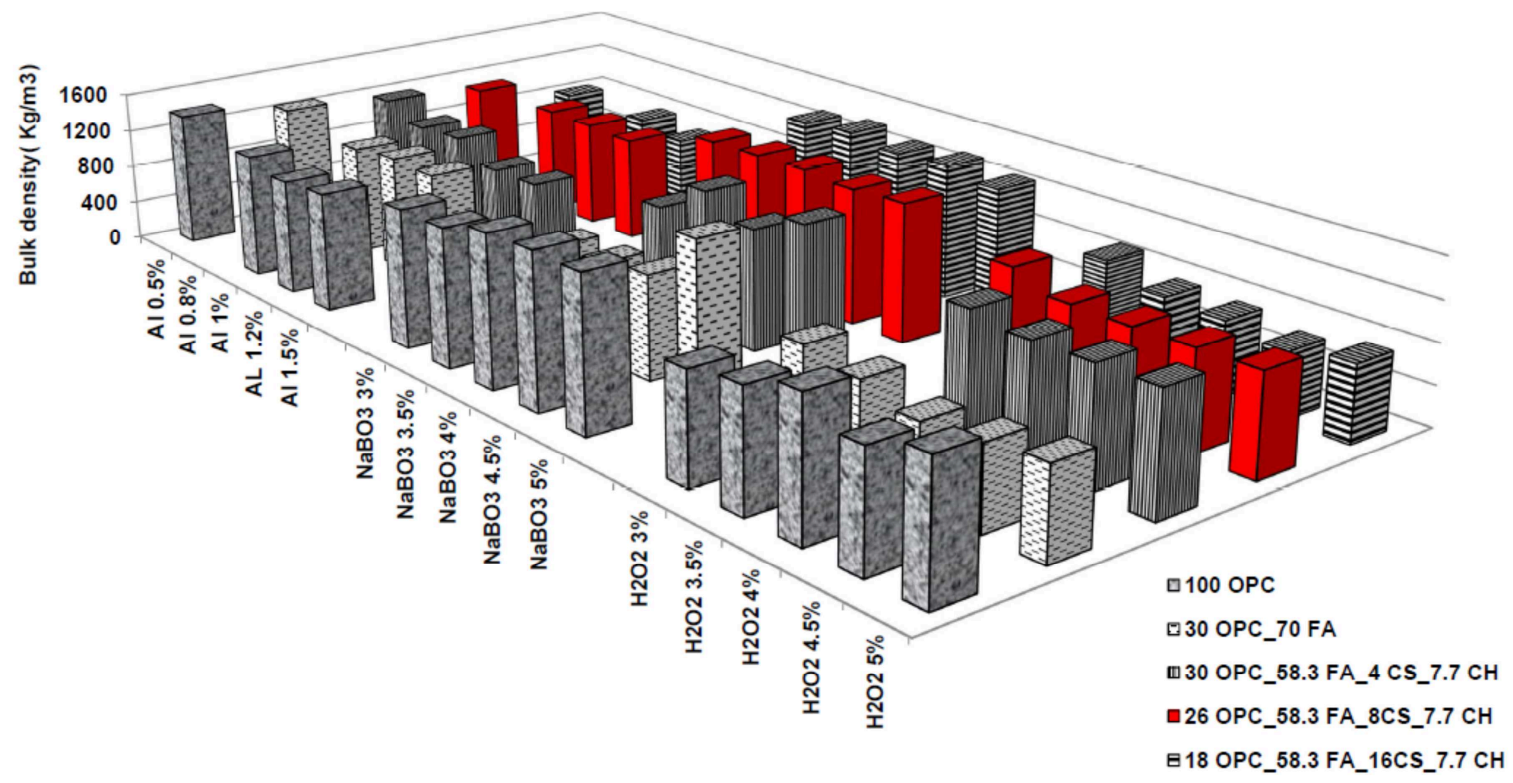

Fig 2. Bulk density

The mixture $26 \mathrm{OPC}+58.3 \mathrm{FA}+8 \mathrm{CS}$ - $7.7 \mathrm{CH}$ with $3.5 \%$ hydrogen peroxide shows an acceptable a thermal conductivity of $0.16 \mathrm{~W} / \mathrm{m} . \mathrm{K}$ because it fits the threshold of the grades 4 and 5 of the Korean Industrial Standard code for foam concrete for floor heating systems [18].

\section{Global warming potential}

The global warming potential GWP (KgCO2e) was assessed using EcoInvent database. Fig 4 presents the global warming potential to thermal resistance ratio.

The results show that mixtures with similar thermal conductivity performance have a much different global warming potential to thermal resistance ratio. This parameter is influenced the percentage of Portland cement. Higher percentages are associated with higher ratios of global warming potential to thermal resistance ratios. Global warming is also influenced by the percentage of oxygen peroxide. Even the mixtures containing sodium hydroxide have a lower ratio because although the GWP of $\mathrm{NaOH}$ is 2.65 higher than the GWP of Portland cement the amount of OPC used in those mixtures is much higher. The mixture $26 \mathrm{OPC}+58.3 \mathrm{FA}+8 \mathrm{CS}+7.7 \mathrm{CH}$ with $3.5 \%$ hydrogen peroxide foaming has a global warming potential of $443 \mathrm{KgCO}_{2 \mathrm{eq}} / \mathrm{m}^{3}$.

\section{Cost analysis}

The cost of materials are listed in Table 2 which shows that the Al powder foaming agent has a much higher cost than the other two foaming agents.

Table 2. Costs of the materials (euro/kg)

\begin{tabular}{|c|c|c|c|c|c|c|c|c|c|c|}
\hline Sand & Cement & $\begin{array}{c}\text { Calcium } \\
\text { hydroxide }\end{array}$ & $\begin{array}{c}\text { Fly } \\
\text { ash }\end{array}$ & Kaolin & $\begin{array}{c}\text { Sodium } \\
\text { hydroxide }\end{array}$ & Water & $\mathrm{SP}$ & $\mathrm{H}_{2} \mathrm{O}_{2}$ & $\mathrm{NaBO}_{3}$ & $\mathrm{AL}$ \\
\hline 0.02 & 0.1 & 0.3 & 0.03 & 0.29 & 0.85 & 0.1 & 0.82 & 0.98 & 1.5 & 32.4 \\
\hline
\end{tabular}

The cost of mixtures is presented in Fig 5. The results show that using Al powder leads to a significant increase of the cost of geopolymers mixtures. The most cost-efficient mixtures (67 euro $/ \mathrm{m}^{3}$ ) were obtained for $26 \mathrm{OPC}+58.3 \mathrm{FA}+8 \mathrm{CS}+7.7 \mathrm{CH}$ with $3.5 \%$ hydrogen peroxide foaming agent. The use of mixtures based on aluminium powder is not feasible because they are not costefficient at all. 


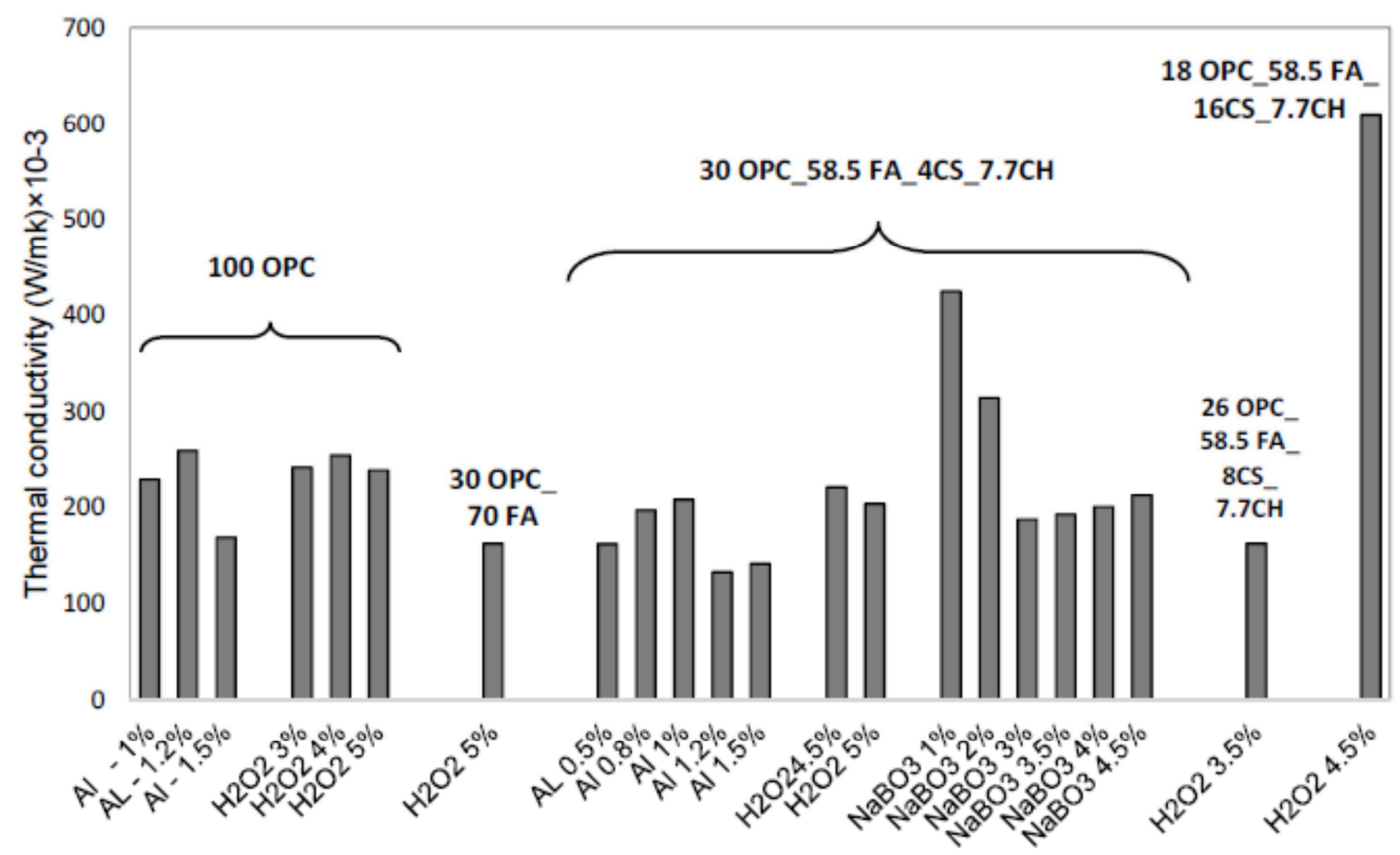

Fig 3. Thermal conductivity

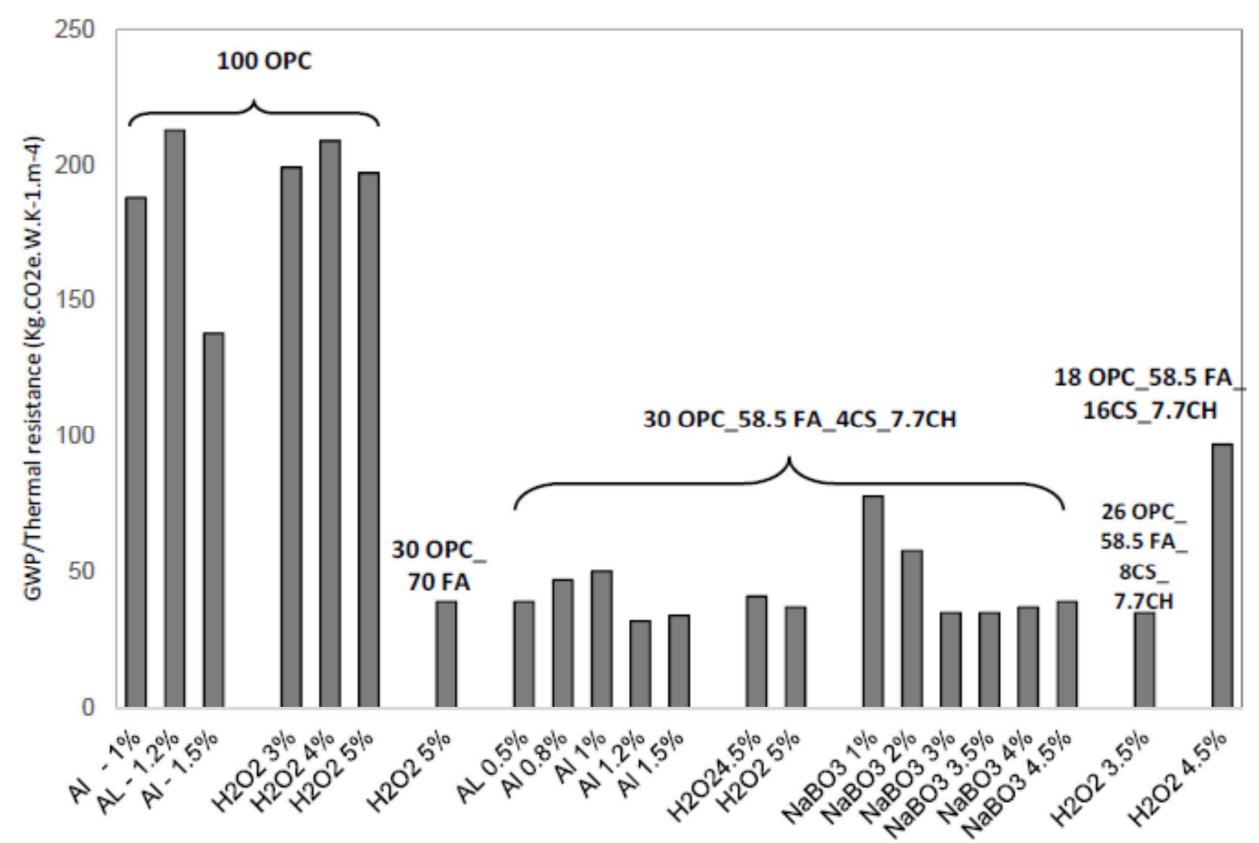

Fig. 4 Global warming potential to thermal resistance ratio

The mixture based on aluminium powder foaming agent with the lowest cost (30 OPC +58.3 $\mathrm{FA}+4 \mathrm{CS}+7.7 \mathrm{CH}$ ) costs more than $200 \mathrm{euro} / \mathrm{m}^{3}$. This represents more than twice the cost of Ytong masonry blocks $\left(70-80\right.$ euro $\left./ \mathrm{m}^{3}\right)$. It is worth remember that foam mortars based on classical two part geopolymers have a cost above 300 euro $/ \mathrm{m}^{3}$ [19]. The results of the cost to thermal resistance ratio are presented in Fig. 6. The best ratio was detected for the mixture $26 \mathrm{OPC}+58.3 \mathrm{FA}+8$ $\mathrm{CS}+7.7 \mathrm{CH}$ around $10 \mathrm{euro} /(\mathrm{m} . \mathrm{K} / \mathrm{W})$.

\section{Conclusions}

The results show that the use of aluminium powder is very effective in obtaining foam materials with low thermal conductivity. This foaming agent allows the production of mortar mixtures with a compressive strength above $6 \mathrm{MPa}$ however its high cost means they are commercially useless when facing the competition of commercial cellular concrete. 


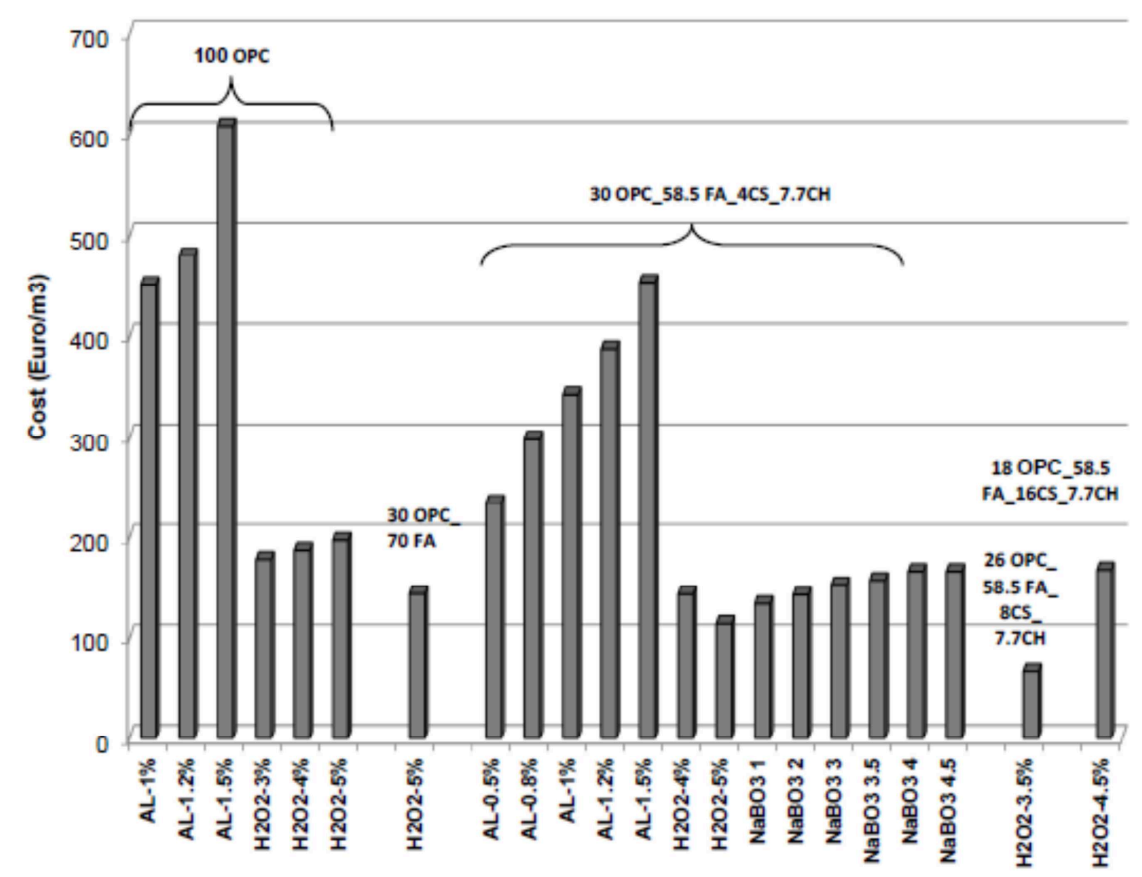

Fig 5. Cost of one-part geopolymer mixtures

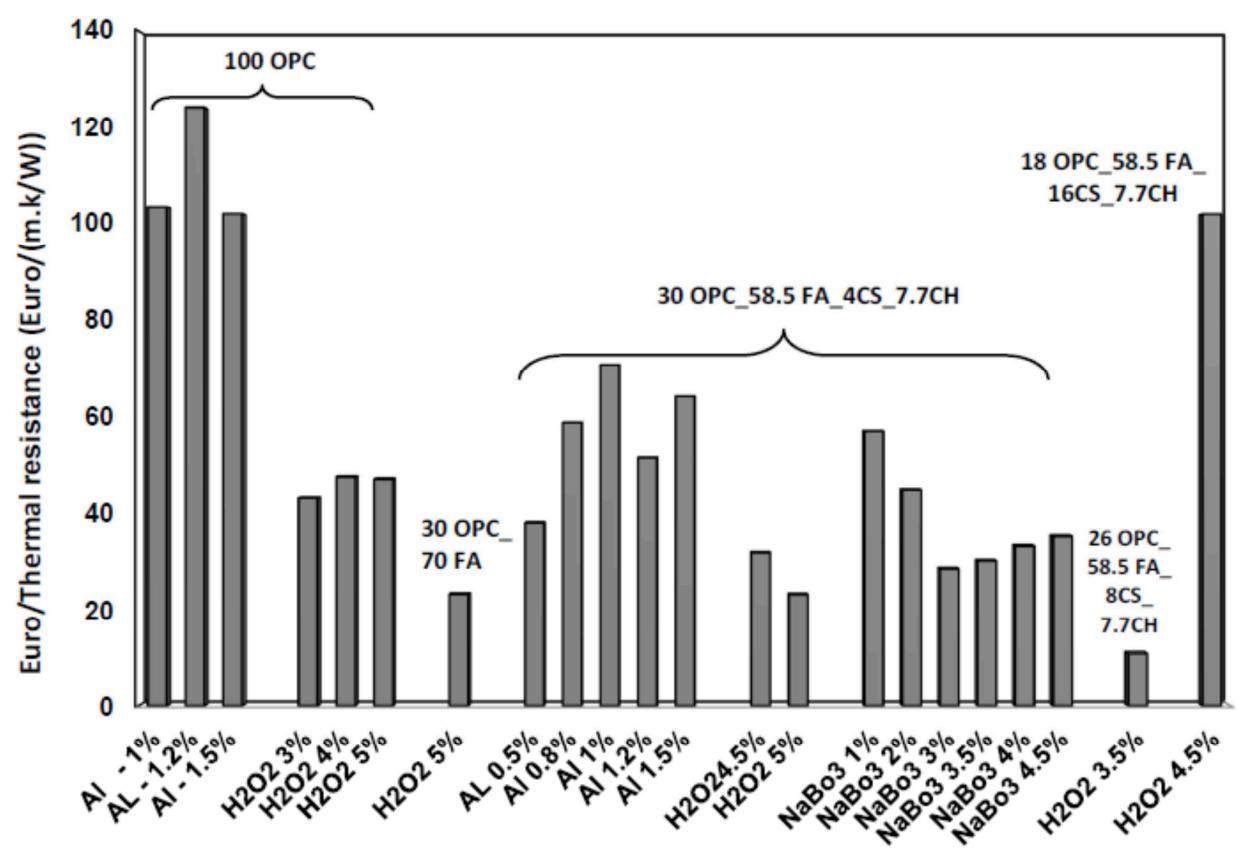

Fig 6. Cost to thermal resistance ratio

The mortar mixture based on aluminium powder mortar with the lowest cost (30 OPC+58.3 $\mathrm{FA}+4 \mathrm{CS}+7.7 \mathrm{CH}$ ) costs more than $200 \mathrm{euro} / \mathrm{m}^{3}$. This represents more than twice the cost of Ytong masonry blocks $\left(70-80\right.$ euro $\left./ \mathrm{m}^{3}\right)$. Its worth remember that foam mortars based on classical two part geopolymers have a cost above 300 euro $/ \mathrm{m}^{3}$ which shows that two part geopolymers are not a costeffective solution for thermal insulation materials.

The mixture $26 \mathrm{OPC}+58.3 \mathrm{FA}+8 \mathrm{CS}+7.7 \mathrm{CH}$ with $3.5 \%$ hydrogen peroxide shows an acceptable compressive strength and thermal conductivity complying with the requirements of the grades 4 and 5 of the Korean Industrial Standard code for foam concrete for floor heating systems $(\geq 1.4 \mathrm{MPa}$ and $\leq 0.16 \mathrm{~W} / \mathrm{m} . \mathrm{K})$. This mixture is cost efficient $\left(67 \mathrm{euro} / \mathrm{m}^{3}\right)$ and has low global warming potential $\left(443 \mathrm{KgCO}_{2 \mathrm{eq}} / \mathrm{m}^{3}\right)$. 


\section{References}

[1] F. Pacheco-Torgal, S. Jalali, Eco-efficient construction and building materials, Springer Verlag, London, UK (2011).

[2] UN, Energy for a sustainable future. The Secretary-General's Advisory Group on energy and climate change, New York (2010).

[3] WHO, Urban population growth, Global health observatory (2014).

[4] OCDE, Environmental sustainable building — challenges and policies, Paris (2003).

[5] F. Pacheco-Torgal, L. Cabeza, M. Mistretta, A. Kaklauskas, G. Granqvist, Nearly zero energy building refurbishment, A multidisciplinary approach Springer Verlag, London, UK (2013).

[6] F. Pacheco-Torgal, Eco-efficient construction and building materials research under the EU Framework Programme Horizon 2020, Constr. Build. Mat. 51 (2014), 151-162.

[7] F. Pacheco-Torgal, A. Fucic, S. Jalali, Toxicity of Building Materials. Woodhead Publishing Limited Abington Hall, Cambridge, UK (2012).

[8] Regulation (EU) 305, Construction Products Regulation (2011).

[9] J. Davidovits, Synthesis of new high temperature geo-polymers for reinforced plastics/composites. SPE PACTEC 79 Society of Plastic Engineers, Brookfield Center (1979) 151154.

[10] J. L. Provis, J.S.J.Van Deventer, Geopolymers: Structure, Processing, Properties and Industrial Applications, Woodhead Publishing, Cambridge, UK (2009).

[11] F. Pacheco-Torgal, Z. Abdollahnejad, A. Camões, M. Jamshidi, Y. Ding, Durability of alkaliactivated binders. A clear advantage over Portland cement or an unproven issue ? Constr. Build. Mat. 30 (2012) 400-405.

[12] J.L. Provis, Durability of geopolymers as $21^{\text {st }}$ century concretes, ERC Starting grant for the period 2013-2018.

[13] F. Pacheco-Torgal, J.A. Labrincha, C. Leonelli, A. Palomo, P. Chindaprasirt, Handbook of Alkali-Activated Cements, Mortars and Concretes ed. 1. Abington Hall, Cambridge, UK: WoodHead Publishing Limited- Elsevier Science and Technology (2014).

[14] D. Kolousek, J. Brus, M. Urbanova, J. Andertova, V. Hulinsky, J. Vorel, Preparation, structure and hydrothermal stability of alternative (sodium silicate-free) geopolymers, J. Mat. Sci. 42 (2007) 9267-9275.

[15] M.-X. Peng, Z.-H. Wan, S.H Shen, Q.G. Xiao, Synthesis, Characterization and mechanisms of one-part geopolymeric cement by calcining low-quality kaolin with alkali, Materials and Structures 48 (2014) 699-708.

[16] Z. Abdollahnejad, P. Hlavacek, S. Miraldo, F. Pacheco-Torgal, A. Aguiar, Compressive strength, microstructure and hydration products of hybrid alkaline cements. Materials Research 17 (2014), 10.

[17] Z. Abdollahnejad, F. Pacheco-Torgal, A. Aguiar, C. Jesus, Durability of fly ash-based geopolymer. Key Engineering Materials 634 (2015) 113-120.

[18] K.-H. Yang, K.-H.Lee, J.-K. Song, M.-H. Gong, Properties and sustainability of alkaliactivated slag foamed concrete. Journal of Cleaner Production 68 (2014) 226-233.

[19] Z. Abdollahnejad, F. Pacheco-Torgal, A. Aguiar (2015) Mix design, properties and cost analysis of fly ash-based geopolymer. Construction and Building Materials 80, 18-30. 